\title{
حضارة الكتاب
}

نظريَّة في التَّأثيرات الحضاريَّة للطّيّاعة والثَّقافة السَّطريَّة القرائَّيَة

\section{book civilization}

\section{A theory on the cultural influences of printing and the reading culture}

كمال عرقات نبهان

\section{Kamal.mohamed.arafat@gmail.com}

ملخص

تعرض الدراسة أفكار ماكلوهان الأستاذ الكندي في علوم الاتصال سفيما يتعلق بتأثير القراءة والكلمة المكتوبة على المجتمع والإنسان، ومن ثََّّ تتناول الأسس التي يقيم عليها ماكلون نظريته، وأهمها علاقة الوسيلة بالإنسان؛ حيث الوسيلة امتداد للإنسان، وكيفية تأثير الوسيلة في الإنسان؛ حيث الوسيلة هي الرسالة. وتتحدث الدراسة بعد ذلك عن المطبوع كوسيلة في نظر ماكلوهان، وتأثيرات المطبوع والقراءة حسب نظريته، سواء التأثيرات النفسية أو التأثيرات الثقافية والاجتماعية. الكلمات المفتاحية: نظرية مارشال ماكلوهان - وسيلة الاتصال - حضارة المطبوع.

* أســـاذ علم المعلومات والمكتبات وعميد المكتبات الجامعيَّة بجامعة مصــر للعلوم والتكنولوجيا.

أ.د/ كمال عرفات نبهان (حضارة الكتاب.. نظريَّة في الثتَّثيرات الحضاريَّة... ) 


\section{$\underline{\text { Abstract }}$}

The study introduces the ideas of the study by McLuhan, the Canadian professor of communication sciences - with regard to the impact of reading and the written word on society and humans, and then the line of foundations that McLuhan writes about his theory, the most important of which is the relationship of the medium to man; Where the means is an extension of the human being, the effect of the means on the human being; Where the medium is the message. The study then talks about print as a medium in McLuhan's view, and the effects of print and reading according to his theory, whether psychological influences or cultural influences.

\section{Key words:}

\section{Marshall McLuhan's theory, method of communication, print civilization.}

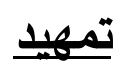

الكتاب قديم منذ سجَّل الإنسان أفكارَه كتابةً على الأحجار والبردي وألواح

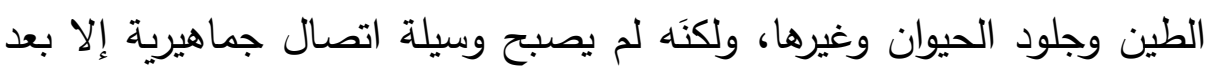

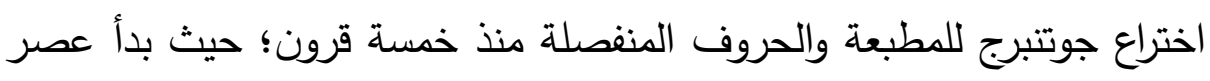
جديد للإنسان، وظلَّ الكتاب أهَّ وسيلة لنقل الأفكار، ويتخطى بها حدود الدكان

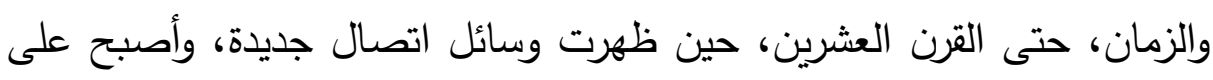

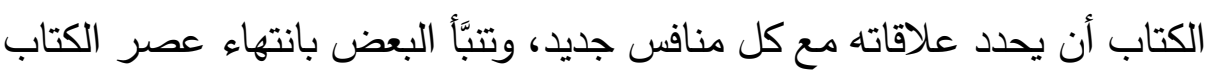
بعد ظهور وسائل الاتصال التكنولوجية، كالسينما والراديو والتليفزيون، وظلًَ الكتاب قائمًا، ولكن قضية استمراره كوسيلة اتصال أصبحت موضع نقاش ونظريًات

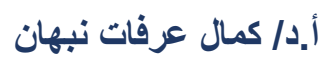
(حضارة الكتاب... نظريَّة في الثأثَئيرات الحضاريَّة... ) 
وأبحاث كثيرة حول الورقية واللاورقية، أو قضية الكتاب الورقي بين البقاء

والزوال.

وفي النِّف الثَّاني من القرن العشرين ظهرت نظرية جديدة أثارت جدلاً

عظيمًا، حتى ليعتبرها البعض أخطر نظريَّة في الفكر الإنسانيّ بعد نظريّة النسبيَّة، وإن كانت هذه المرة في مجال العلوم الإنسانيَّة، هذه النظرية هي نظرية مارشال ماكلوهان، وهو أستاذ كندي في علوم الاتصال، وتكتسب نظريته خطورتها من أنها تحاول أن تضع تفسيرًا جديدًا لمراحل حضارة الإنسان وتطوراته الاجتماعية على أساس نوع وسيلة الاتصال التي تسود في كل مرحلة منها، وما تفرضه من نسب إدراكية وشعورية وانفعالية، فكلُّ تغيير يحدث في وسائل الاتصال يحدث في مقابله تغيير اجتماعي، وكل وسيلة اتصال لها حضارتها التي تقوم عليها. فقد انتقلت الحضارات من الحضارة السمعية الثفهية إلى الحضارة الكتابية منذ اختراع الإنسان للكتابة إلى الحضارة الطباعية بعد ظهور المطبعة، حتى وصلت إلى حضارة الوسائل التكنولوجية الحديثة، وهي وسائل الاتصال المسموعة والمرئية كالتليفزيون والسينما والراديو والتليفزيون ... ويهينا أن نتناول من هذه النظرية ما تذهب إليه بخصوص "حضارة المطبوع"، فماكلوهان يقيم كل التراث العقلي والحضاري الغربي على فرض واحد، هو أنَّ التجربة الرئيسية للإنسان الغربي قامت أساسًا على اختراع الطباعة منذ القرن الخامس عشر حتى القرن العشري، ويتحقق هذا الجانب من ناحية، ونظرًا لأهمية المنهج الذي يستخدمه ماكلوهان في التثير الاتصالي للحضارة

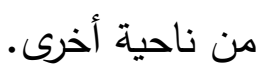

أ.د/ كمال عرفات نبهان

(حضارة الكتاب.. نظريَّة في التَّتثيرات الحضاريَّة... ) 


\section{نظرية ماكلوهان}

يمكن القول بأن أعمق الدراسات التي تتاولت بالتفعير والتحليل تأثيرات القراءة والكلمة المكتوبة على المجتمع والإنسان، هي دراسسات مارشال ماكلوهان Mar-shall Mc Luhan الذي اهتم بالتنكير النظري القائم على الدراسات

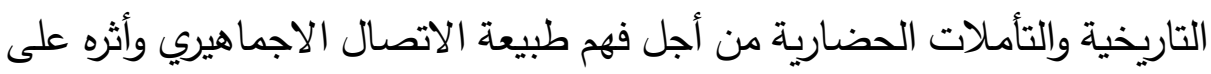

$$
\text { العلاقات الإنسانية][2]. }
$$

وقد دفعت دراسات ماكلوهان كمًّا هائلًا من الأبحاث العلمية المتتوعة،

أفاد منها في الوصول إلى نظراته الثاقبة المدهثة التي لفتت انتباه الباحثين والعاملين في مجالات الإعلام ورجمال الأعمال والمثققين [3] إلى أهمية تفسيراته لهنه الهامة ومنهجه في الربط بين الوسيلة وتأثيراتها الحضارية والاجتماعية والنفسية

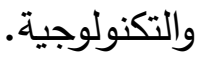

وليس الاهتمام بتأثيرات الكلمة المكتوبة خصوصًا بعد ظهور الطباعة قاصرًا على ماكلوهان فحس، فقد انتبه كثيرون إلى ذلك، ومنهم ول ديورانت Will Durant المؤرخ الأمريكي، الذي قال "إن الطباعة كانت ضمن الأسباب

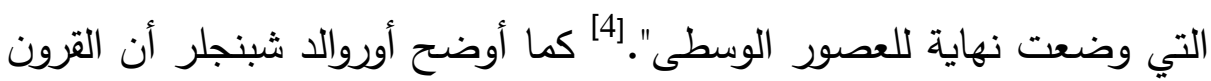

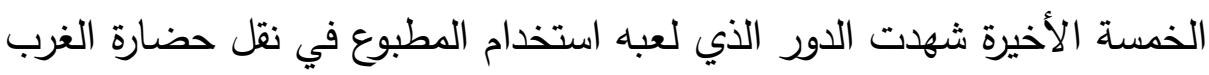

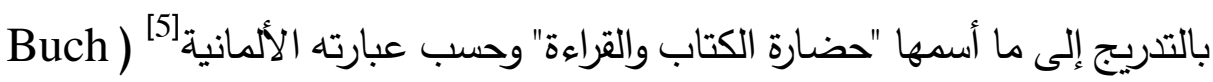
Und lessen Kultue)، كما ظهرت في وقت مبكر اكتثافات ميلمان باري Milman Parry بالغة الأهمية في رسالته العلمية للدكتوراه بالفرنسية عام 1928، حول الخصائص المميزة للفكر الثفاهي كما درسه في شعر هوميروس اليوناني

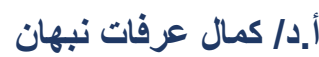
(حضارة الكتاب... نظريَّة في الثأَّيرات الحضاريَّة... ) 
القديم الذي يقال إنه عاش حول 850 ق.م، [6] وهي خصائص تلقي الضوء على الجوانب المقابلة في الفكر الكتابي المقروه. كما ظهرت دراسات كثيرة تهتم بهذا الجانب أو ذاك كم تأثيرات الاتثال الثفهي أو الكتابي، مثل هافلوك ولورد وجاك جودي ومايلز فولي، وأونج الذي ألَّف كتابًا عن تأثير الطباعة في عمليات الفكر في القرن الساد عشر ، وأصدره عام 1958، وكانت هذه الدراسات تتنمي إلى مجالات مختلفة كالأدب والأنثروبولوجيا وغيرهما.[7] ومن الدراسات الهامة في هذا المجال أيضًا، دراسة ميدانية مبكرة (1940) قام بها وبيلز وبيلسون وبرادشو بعنوان "ماذا تقعل القراءة بالناس ( What

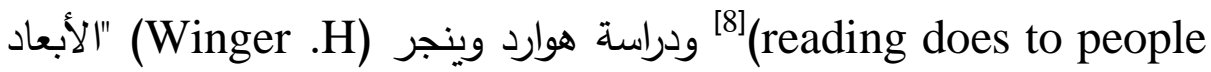
التاريخية لدور الكتاب في المجتمع"، والتي رصد فيها بعض التغيرات الاجتماعية الحيوية التي تتتج عن الأفكار التي ينشرها الكتاب والقراءة.99 ولكن دراسات ماكلوهان لتأثيرات المطبوع والكلمة المقروة قد اكتملت في إطار منهج تحليلي شامل يتتاول القراءة كوسيلة اتصال، كما يتناول وسائل الاتصال الأخرى وتأثيراتها المختلفة، مما جعلنا أمام رؤية متكاملة لأحداث الماضي والحاضر وما يتوقعه في المستقبل مع تطور وسائل الاتصال الجماهيرية الإكترونية، والصراع بين خصائص كل نوع من الوسائل، وما تحدثه من عالم جديد يقوم على أنقاض عالم سابق خلقته وسيلة سابقة تمت أو تتم إزاحتها.

\section{كوكب جوتنبرج:}

ويبدأ ماكلوهان تتاوله لتأثير القراءة والكلمة المكتوبة منذ اللحظة التي أنجز فيها جوتتبرج ابتكاره للحروف المتحركة وللمطبعة، باعتبار أن وسيلة اتصال جديدة 
في شكلها وطبعيتها وانتشارها قد ظهرت لكي تلعب دورها كعامل مؤثر في التاريخ والحضارة وتغيير الإنسان والمجتمع، وبالرغم من أن الجميع قد أدركوا أن ظهور المطبوع كان إيذانًا بظهور تغيرات خطيرة، إلا أن هذه التغيرات تأخذ في نظرية ماكلوهان شكل ثورة كاملة في جميع المجالات، غيرت ملامح المجتمع الإنساني، وبَّلّت خصائص نفسية كثيرة لدى الإنسان، وشَّلت علاقات جديدة، وخلقت أشكالًا اجتماعية جديدة من خلال تراكم التأثيرات والتفاعلات، ومن خلال عمليات البناء والهدم معًا. وقليل من الناس كان لهم هذا التأثير الفعال الذي أحدثه ماكلوهان في عقول متنوعة كثيرة، حتى في عقول أولئك الذين لم يوافقوه، وقد استمر تيار البحث في هذا المجال حتى وصل إلى مراحل متطورة، منها ما ذهب إليه جوليان جينس عام 1977، من الربط بين مراحل الشفاهية والكتابية وبين بين تغيرات عصبية وفسيولوجية في عقل الإنسان[10]، ولكن تفسيرات ماكلوهان تظل محتفظة بجدتها وديناميتها، وقدرتها على العصف الفكري، تارة بدقة ومعقولية التفسير والطرح، وتارة بغرابة الفكرة ومخالفتها للمألوف، وملامح الإبداع التي تتبدى في كل أفكاره، وحتى لو تحفظنا أمام بعضها، أو خالفناه في بعضها الآخر ، فإنه في كل الأحوال ينقلنا من غرفة التفكير التقليدي، إلى ساحة التفكير الإبداعي. وبداية يرى ماكلوهان أننا نفتقر إلى فَهم التأثيرات النفسية والاجتماعية للمطبوع، مما يحير أي دارس للتاريخ الاجتماعي للكتاب المطبوع، فمن النادر على مدى الخمسة قرون الماضية -على حد قوله- وجود ملاحظة أو فهم واضح

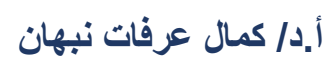
(حضارة الكتاب.. نظريَّة في الثتَّثيرات الحضاريَّة... ) 
لتأثيرات المطبوع على وعي وإدراك الإنسان (Seneibiliy)، كما يرى أن نفس الملاحظة يمكن أن تصدق بالنسبة لكل وسائل الاتصال الأخرى[11]. وقد تتاول ماكلوهان تأثيرات الكتاب المطبوع في معظم مؤلفاته، ولكن أهمها في هذا المجال مؤلفاته التالية: Mc Luhan, Marshal:

1. The Gutenberg Galaxy: The making of typographic man.

2. Undrstanding media: The extensions of man. ${ }^{[12]}$

3. The medium is the message.

4. The cool medium.

ومن الواضح من عنوان الكتاب الأول "كوكب جوتتبرج"، نسبة الكوكب الأرضي في رأيه إلى جوتنبرج في المرحلة التالية على اختراع الطباعة؛ لأن الكوكب قد أعيد ترتيبه (The galaxy reconfigurated) الجديدة التي أوجدها المطبوع في نبية الإنسان والمجتمع وسائر مظاهر الحياة والمؤسسات بأنوعها، وقد ظلت مملكة جوتتبرج متسيدة على الكوكب حتى هزت عرشه وسائل الاتصال الإكترونية الحديثة، وهذا موضوع آخر يحتاج إلى دراسته بالتفصيل. ولا يمكن فَهم ما يذهب إليه ماكلوهان في تفسيره للتأثيرات التاريخية والحضارية للمطبوع والقراءة، إلا بعد التعرف على القواعد أو الأسس التي يقيم عليها نظريته وينطلق منها، والتي بدونها تبدو استتاجاته غاضمة مبهمة، وأهم

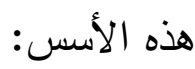


أولًا: علاقة الوسيلة بالإنسان؛ حيث "الوسيلة امتداد للإنسان". ثانيًا: كيفية تأثير الوسيلة في الإنسان؛ حيث الوسيلة هي الرسالة. وفيما يلي عرض لهاتين القاعدتين كما يحددها ماكلوهان. أولًا: الوسيلة امتداد لبلإنسان:

يتتاول ماكلوهان كل الوسائل التي يستخدمها الإنسان في حياته، باعتبارها امتدادات Extensions لقدرات بشرية معينة سواء كانت قدرات نفسية أو مادية[14] "فكل الأشياء المادية والوسائل التي يبتكرها أو يكتشفها، هي توسعات وإمكانيات تضاف إلى قدراته الطبيعية. ويبدو الامتداد كما لو كان تضخميًا لعضو أو حاسة أو وظيفة (Orang, sense, or function) لدى الإنسان[15]، فالعجلة تعتبر امتدادًا للقدم[16]، وتؤدي شبكات النقل الآن ما تعودنا أن نؤديه بأقدامنا وظهورنا"[17]، والملابس هي امتداد للجلد [18]. كما تعتبر الملابس والمنازل امتدادًا للعمليات البيولوجية التي تضبط حرارة جسم الإنسان، والمال هو امتداد واختزان لطاقة العمل، والأسلحة التي تتطور حتى تتتهي بالقنبلة الذرية هي امتداد للأسنان وقبضة اليد[19] والدائرة الكهربائية هي امتداد للجهاز العصبي المركزي]20] أما الكتاب فيتعبر امتدادًا للعين]21]، وللك فإن ظهور الطباعة والكتاب المطبوع قد فجَّر طاقة هائلة وامتدادًا عظيمًا، أتاح للإنسان الرؤية والمعرفة في أبعاد لا حدود لها، متخطيًا بذلك حدود الزمان والمكان.

وهو يعتبر أن توسع أو امتداد أية حاسة يويح Displaces أو يغير alters بها العالم ونرى أنفسنا؛ حيث يلاحظ مثلًا أن اختراع الحروف الهجائية قد خلق 
الثقافة الكتابية (literate culture)، التي كانت مختلفة تمامًا عن الثقافة القبلية الشفهية، كما سوف نرى في هذه الدراسة. وهكذا نجد ماكلوهان في نظريته يعالج وسائل الاتصال بالجماهير من حيث هي أدوات تكنولوجية بصرف النظر عن المضمون الذي يحتويه أو توصله،

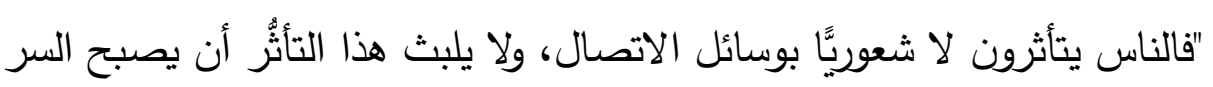
الحقيقي الكامن وراء السلوك الإنساني [22]. ووسيلة الاتصال عند ماكلوهان، هي جزء من العملية التكنولوجية التي يتحمل أن تغير وجه المجتمع كله، سأنها في ذلك شأن التطورات الفنية الأخرى، والاهتمام حينئذ مركز على تأثير الوسيلة بصرف النَّظر عن مضمونها أو طريقة استخدامها، سواء لنشر المعلومات أو للترفيه أو للتعليم، وبذلك يمكن التمييز بين منهجين في النَّظر إلى وسائل الاتصال: (أ) منهج مخالف لمنهج ماكلوهان، يرى أن الوسيلة تنقل مضمونًا وأن المضمون هو الذي يؤثر، بما يحمل من أفكار أو رسائل جيدة أو

$$
\text { رديئة. }
$$

(ب) منهج ماكلوهان الذي يرتكز على أن الوسائل هي جزء من سلسلة التطور التكنولوجي، وهي تؤثر بطبيعتها كوسائل لها آلية معينة، وبذلك فإن مضمون وسيلة الاتصال لا ينفصل عن تكنولوجية الوسيلة ذاتها، وطبيعة الوسيلة التي يتصل بها الإنسان سواء كانت شفهية أو معروءة أو سمعية بصرية ... إلخ، هي التي تشكل الأفراد والمجتمعات أكثر مما يشكلها مضمون الاتصال أو الرسائل والأفكار التي تصل

$$
\text { إلى مستخدم الوسيلة[23] }
$$

أ.د/ كمال عرفات نبهان (حضارة الكتاب.. نظريَّة في الثتَّثيرات الحضاريَّة... ) 


\section{ثانيًا: الوسيلة هي الرسالة}

ومن أهم الأسس التي يقيم عليها ماكلوهان نظريته، ومن أكثرها غرابة

The medium is ” وإثارة للجدل معًا، مقولته الثهيرة بأن الوسيلة هي الرسالة "message فوسيلة الاتصال هي وسلط يحيط بالإنسان ويؤثر فينا تأثيرًا كاملً، فهي بالغة الثمول في تأثيراتها الثخصية والسياسية والاقتصادية والجمالية والنفسية والأدبية والأخلاقية والاجتماعية، حتى إنها لا تترك جانبًا فينا بغير أن تلمسه وتؤثر فيه وتغيره، فالوسيلة هي الرسالة، وأي تفهم جديد للتغيير الاجتماعي والتقافي هو أمر متعذر بدون معرفة الطريقة التي تعمل بها الوسائل كوسط Environment

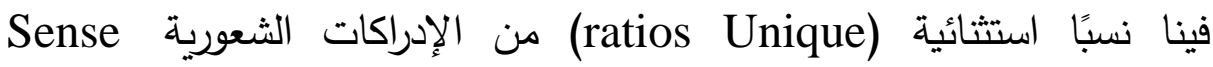
perceptions بها، ومن الطريقة التي ندرك بها العالم، وحينما تتغير هذه النسب يتغير الإنسان [25]

وهكذا يحدث تأثير وسيلة الاتصال نتيجة لخصائصها الآلية كوسيلة

مادية وليس بمضمونها الذي توصله، فالأثر يحدث عن طريق الوسط الذي تخلقه، وهكذا "فعندما يخترع الإنسان الوسيلة، فإن الوسط الذي يخلقه هذا الاختراع يصبح هو ذاته وسيلة، ويتحدد دور الإنسان من جديد من خلال هذا الوسط[26]. "والوسيلة هي الرسالة"، تعني أيضًا أن لكل وسيلة جمهورًا من الناس الذين يفوق حبهم لهذا الوسيلة اهتمامهم بمضمونها، فكما يحب بعض الناس أن يقرأوا 
من أجل الاستمتاع بممارسة تجربة القراءة، فإن البعض كذلك يحب التليزيون بسبب الثاشة التي تتحرك عليها الصورة المصاحبة للصوت[27]. وعلى هذا الأساس يرى ماكلوهان أن تشكيل المجتمعات يتوقف على طبيعة الوسيلة السائدة نفسها وليس على مضمونها، وأن الكتاب قد يتضمن مادة تفافهة أو قيَّمة، ولكن ليس لهذا دخل له في التغيرات الحقيقة التي يسببها التليفزيون، فالرسالة الأساسية في الكتاب هي الاتصال السطري أو "المطبوع"، وفي التليفزيون هي "التليفزيون" نفسه، هي العملية نفسها، ولا يهم إذا عرض التليززيون عشرين ساعة يوميًّا من أفلام رعاة البقر التي تتطوي على عنف وقسوة، فالمضمون غير هام، ولكن التأثير العميق لعملية مشاهدة التليفزيون هو الرسالة الحقيقية[28]. وينبغي أن نشير إلى أن مقولة "الوسيلة هي الرسالة" هي من أكثر مقولات كاكلوهان إثار للجدل؛ لأنها من ناحية تفسر لنا جوانب كثير من تأثير وسيلة الاتصال على سلوك وإدراك الإنسان، الذي يمكن أن نسميه إنسان الوسيلة، سواء كان إنسان الاتصال الثفهي، أو إنسان الطباعة، أو إنسان التليفزيون ... إلخ، ولكنَّها من ناحية أخرى تنفي جانبًا هامَّا من الحياة الفكرية للإنسان؛ لأنَّها ليست مجموعة من الاستجابات الآلية للوسيلة، بل إن لها غاياتها وقيمها، وذلك يؤكد أيضًا أهمية المضمون الذي توصله أداة الاتصال، فلا نستطيع أن نتجاهل ما تحتويـه الرسالة من مضمون جيد أو رديء، بنَّاء أو مدمرًا، سواء في القاهرة أو التليفزيون أو بأي وسيلة أخرى.

أ.د/ كمال عرفات نبهان

(حضارة الكتاب.. نظريَّة في التَّتثيرات الحضاريَّة... ) 


\section{المطبوع كوسيلة في نظر ماكلوهان}

ومن هذا المنطلق يفسر ماكلوهان تأثير الحروف المتحركة والطباعة كوسيلة تحمل رسالتها في طبيعتها المادية وتأثيراتها النفسية والاجتماعية في الإنسان والمجتمع، التي تحدث أساسًا نتيجة لشيء واحد وعملية واحدة هي (المطبوع - الوسيلة - الرسالة)، أو (القراءة - الوسيلة - الرسالة)، وحينما ينظر ماكلوهان إلى التاريخ، يأخذ موقفًا يمكن أن يسمى بـ"الحتمية التكنولوجية" (Technological determinism) الهامة هي التي تؤثر تأثيرًا أسياسيًا على المتجمعات [29]. وهذه الحتمية التكنولوجية التي تكاد توحي بها نظرة ماكلوهان، تقف في مواجهة حتميات أخرى في تفسير السلوك والتاريخ والحضارة.

ويستمر ماكلوهان في مقولاته وتقسيراته المبهرة التي تثبه الصدمات

الكهربائية؛ حيث يرى "أن أعظم إنجازات التقدم الحضري، إنما هي عمليات حطمت المجتمعات التي تحققت فيها"[30]. وعلى هذه الأسس يمكن فهم ما يذهب إليه ماكلوهان من أن المطبوع بما له من خصائص هي جزء من طبيعته ومن طبيعة الحروف التي تتكون منها سطوره، قد خلق أشكالًا ثقافية وحضارية واجتماعية هي بحق ثقافة وحضارة المطلبوع سواء بالمعنى الاجتماعي أو المعنى المعرفي لمصطلح الثقافة، وبكل ما يعنيه مصطلح الحضارة من أبعاد، كما يمكن من خلال نظريته أن نجد ما يسمى: ثقافة سطرية أدبية.

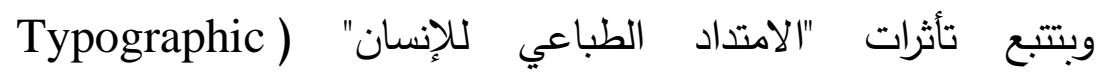
extension of man 
يمكن أن نعرض هذه التأثيرات التي يقسمها ماكلوهان إلى تأثيرات نفسية (Psychically) التأثيرات الاجتماعية كل التأثيرات الاقتصادية والسياسية والفنية والأدبية والثقافية والتعليمية والتكنولوجية والإدارية والاتصالية.. إلخ، وإن كنا نلاحظ صعوبة التثرقة الحاسمة بين ما هو نفسي وما هو اجتماعي، نظرًا لثدة الارتباط وحميمية التفاعل

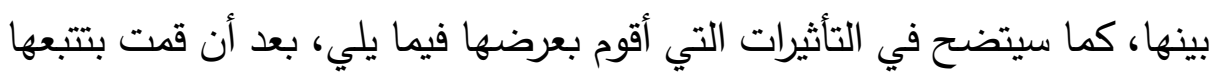

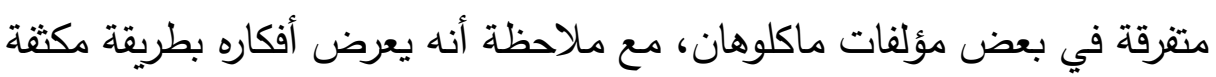

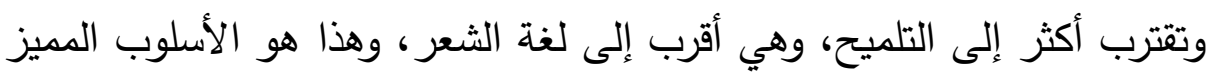
لماكلوهان، إلى جانب صياغته لنصطلحات وتركيبات جديدة، وقد حرصت على إلى إثبات كثير منها بالإنجليزية داخل النَّ؛؛ تحقيقًا للفائدة. تأثيرات المطبوع والقراءة حسب نظرية ماكلوهان أولًَ: النَّثَثيرات النَّفسية

\section{1 - فصل الفكر عن الانفعال وتجزئة الحواس}

يتصف الإنسان البدائي بأنَّه يفكر وينفعل في آن واحد، ولا يستطيع الفصل

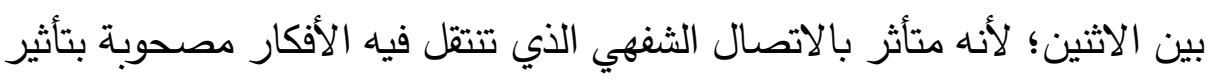

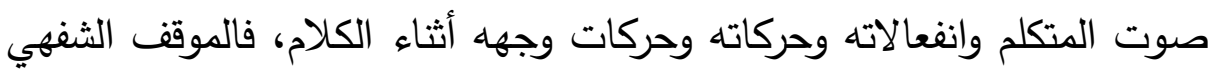
موقف كلي موحَّد ساخن، ويلاحظ ماكلوهان عكس ذللك في الاتصال القرائي

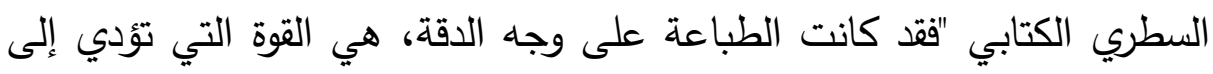

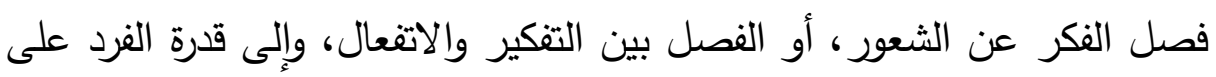

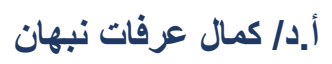
(حضارة الكتاب... نظريَّة في الثأَّيرات الحضاريَّة... ) 
الفعل المستقل، أو أن يستطيع الإنسان أن يفعل بغير أن ينفعل، أي أن يفعل بدون أن يتأثر، أن يتصرف متحررًا من رد الفعل، والطباعة هي التي فصلت الإنسان القارئ عن المجتمع التقليدي القبلي ذي الروابط الأسرية المتماسكة في كل مظاهر الحياة الثخصية والاجتماعية[33]، فالطباعة جعلت الإنسان يخرج عن الجماعة التقليدية وعن أفكارها وصياغتها المحكمة؛ لكي يتصل، ينفصل عن روابطه وإطاره لكي يتصل بآخرين ليسوا من جماعته أو من إطاره، وهي أفكار لا تأتيه شفاهية ساخنة بل باردة على صفحة من الورق، وهو لا يستقبل أصواتًا بل يقرأ كتابة صوتية وهي الحروف، وهذه "الكتابة الصوتية هي وحجدها القادرة على فصل وتجزئة الحواس، والتخلص من التعقيد في دلالات الألفاظ الذي هو من خواص الاتصال الثفهي، وهذه العملية الكتابية تحدث التجزيء التحليلي للحياة الثعرية"[34]. فالاتصال القرائي يحدث نوعًا من الفصل بين عناصر الاستجابة في العملية الاتصالية، مما يمكن أن نسميه بالثيزوفرانيا القرائية. 2- الموضوعية واستقلال الئي والمنهج العلمي:

وربما كانت أعظم هبات الطباعة للإنسان في نظر ماكلوهان، هي ذلك التجرد أو الاستقلال في الرأي (detachement)، وعدم الانضواء أو التبعية كما وهبته القدرة على الفعل المستقل، ومنذ عصر (Non-envolvement) النهضة (الأوروبية)، فقد مجَّد العلم هذه الهبة[35]. وتتضح هذه الفكرة إذا تابعنا أفكار ماكلوهان حيث يقول: "ولقد أوجدت الطباعة الكتاب الذي يمكن حمله، والذي يستطيع النَّاس قراءته على انفراد وبمعزل عن الآخرين .. وقد أضاف المطبوع الثيء الكثير إلى مبدأ الفردية الجديد (cult of individualism)، وأصبحت

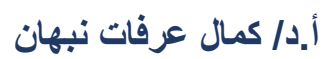
(حضارة الكتاب.. نظريَّة في التَّثيرات الحضاريَّة... ) 
وجهة النظر الخاصة والمحددة أمرًا ممكنًا، كما أن الإملمام بالقراءة قد منح القدرة للفرد على استقلال الرأي وعدم الانضواء"[36]. وعلى عكس ذلك يعنى فعل التعلم أو التعرف في الثقافة الثفهية إنجاز انتماء حميم ومشاركة وجدانية جماعية مع "المعروف"، ويتضمن ذلك أثكالًا من الاحتواء، أما الكتابة فتفصل بين العارف والمعروف، وتبني شروطًا للموضوعية، بمعنى عدم الارتباط الثخصي والابتعاد[37]، بل ويصل الأمر إلى المقابلة الحادة التي يضعها جاك جودي (1977) بين خصائص الثفاهية والكتابية، تصل إلى الانتقال من السحر إلى العلم، أو مما يسمى "ما قبل المنطقي" إلى حالة الوعي التي تزداد عقلانية، أو من "العقل المتوحش" إلى الفكر المستأنس [38]. ولقد حفل تاريخ الفكر الإنساني بمحاولات عديدة لتأكيد القيمة الأخلاقية للتجرد والموضوعية، وهي أساس المنهج العلمي في الفكير، ويرى ماكلوهان أن الذي مكَّن لهذه القيمة من الازدهار هي تلك الصفات التي اكتسبها إنسان الطباعة، "فهو يتصف بالاستقلال في الرأي Loftiest detachement، والتجرد الأخلاقي ethical integrity على المزاج العلمي للمجتمع القارئ المستتير enlightened.. وعلى التخصص (spicalization [39] (sensibility)

"تلك كانت الهبة عظيمة الأثر التي وهبتها القراءة والطباعة للإنسان، وهي القدرة على الفعل المستقل، وعدم الانضواء، وفصل الفعل عن الثعور والانفعال، والذي بدونه يصبح الإنسان مشوشًا مترددًا (hwsitant \& hampered) [40. 
وجدير بالتتويه أن الحياد والموضوعية والمنهج العلمي لم تكن كلها نسبًا

إدراكية وخصائص حضارية غائبة فأوجدها المطبوع، بل كانت موجودة وتأسست جذورها في الفكر الإسلامي منذ قرون بعيدة، ولكن الذي نفهمه أن ماكلوهان يشير إلى قوة التدعيم التي خلقها المطبوع لهذه الخصائص، والتمكين لها مما أدى إلى ازدهارها وتحولها إلى صفة غالبة نسبيًا في الفكر والحضارة المتأثرة بالمطبوع.

\section{3. التفكير الخطي والترتيب:}

ويرى ماكلوهان أنه ليس هنالك ما يفوق ثقافة الطباعة من حيث خاصيتها: place for everything and ماكن لكل شيء، وكل شيء في مكانه" everything in its place الاستمرارية والخطية Linearity بالتكرار المجزأ[42]. وهي خواصل الحروف المتتابعة للطباعة. وكان ذلك هو الوسط environment الذي فرضته الوسيلة المطبوعة نفسها، كلمة بعد أخرى، وجملة بعد أخرى، وفرة بعد أخرى، وشيء واحد في الوقت الواحد، في خط منطقي متصل.. وذلك بعكس المجتمع الثفاهي الذي يعتمد على الأذن ear oriented، الذي يميل إلى استقبال خبرات كثيرة في نفس الوقت والتعبير عنها][33]. "ولا يلبث الوسط الذي يخلق الإنسان أن يصبح هو وسيلة نحو تحديد دوره من خلاله، وقد أدى اختراع الحروف المطبوعة إلى التفكير الخطي Linear thinking أو المتتابع (Sequential) وأدى إلى فصل الفكر عن

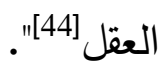




\section{4. التركيز البصري والمنظور (في الرسم المجسم):}

"ولقد كان تحصيل المعلومات اعتمادًا على حاسة السمع عند الرجل الأمي، لا يتيح له التركيز؛ لأن الأذن لا يمكنها أن تركز ، ولكن العين يمكن أن تركز في عملية القراءة، وهي عملية استخدام لعيوننا لتعلم الأشياء التي لا تستطيع أن تراها، وهذه المقدرة الفريدة تعتمد على العين؛ لأنها تركز وتتبع الأشياء بتوالٍ[45]". ومن الاستمرارية والتماثل والترابط في عملية القراءة، ينبع التركيز البصري (46)] وقد أكد اختراع الطباعة التركيز البصري الجديد،

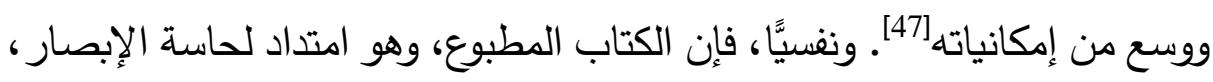
قد كثَّف المنظور والنقطة الثابتة للرؤية، واتحد ذلك مع التركيز البصري الذي يقع على نقطة الرؤية point of view، ونقطة الزوال، التي تخلق وهم المنظور (وهو تمثيل الأشياء ذات الأبعاد الثلاثة على سطح ذي بعدين Perspcctive فتبدو وكأنها نافذة إلى العمق)، ومن خلال ذلك، تحقق خداع آخر ، وهو أن الفراغ مرئي Visual ومنتظم متسق Uniform، ومستمر Continuous [48]. وذلك شكل جديد من التصور الثلاثي الأبعاد، الذي يختلف عما سبقه من تصوير ذي بعدين، والذي يسميه ماكلوهان بالموزايكو، وهو المنهج المتبع في التصوير الإسلامي القديم كما نلاحزه عند بهزاد وغيره من عباقرة التصوير الإسلامي. 5. الأبعاد الثلاثة في الكُونْرَّبط (في الموسيقى الغربية):

ولم تقتصر تأثيرات الطباعة على تكثيف المنظور في فن التصوير، بل تخللت كل وجه في الفنون والعلوم في القرون الخمسة الماضية كنتيجة لحضارة المطبوع؛ فالموسيقى الغربية فيها كونتربنط Counterpoint (أو طباق)، "وهو 
يعتمد على صوت مقابل صوت، وعلى تعدد الخطط اللحنية في أنماط متعددة، بحيث يكون لكل تركيب نغمي تركيب يقابله ويوازنه وإن لم يشابها، ويتقابل صوت غنائي من طبقة ما مع صوت غنائي من طبقة أخرى، وتنقلب المسافات أو الأبعاد الموسيقية اللحنية الفاصلة بين أصوات اللحن فتحول كل مسافة صاعدة إلى هابطة والعكس صحيح، مع تفاصيل فنية أخرى تحكم الكونتربنط[49]، وهو ذو ثلاثة أبعاد ويشبه في ذلك التصوير المجم الذي خلقه المنظور الناتج عن تأثيرات المطبوع، وذلك بعكس الموسيقى الثرقية التي لا توجد فيها الأبعاد الثلاثة بل تشبه التصوير بالموزايكو ذي البعدين.

\section{6. تنمية التعيير الذاتي والإبداع:}

وتبدو تفسيرات ماكلوهان لتأثيرات حضارة المطبوع متواصلة في نفس

الاتجاهات السابقة، ومرتكزة على نفس الأسس، وإن امتدت إلى مجال آخر من مجالات الحياة النفسية والانفعالية لإنسان الطباعة، وهو مجال الفن والأدب. ونلاحظ هنا أنه يربط بين بعض خصائص المطبوع والحروف المقروءة مثل التجزيئية والتحليلية، وبين حدوث الانفصالية في الإدراك، كما يربط بين خطية وتماثل ودقة ترتيب الحروف، والامتداد الطباعي للإنسان وبين ظهور أشكال ثقافية عظمى منذ القرن الأول للطباعة، وهو في نفس الوقت بداية عصر النهضة في أوروبا.

كما نلاحظ أنه يذكر تفسيراته واستنتاجاته هذه في جمل خاطفة سريعة، شديدة التركيز تشبه صيغة القوانين. ففي كتابه: كيف نفسهم وسائل الاتصال يقول: "ولقد كان للقوة التجزئية fragmentray والتحليلية analytic للكلمة المطبوعة، 
تأثيرها في حياتتا النفسية، فقد أحدثت تلك الانفصالية في الإدراك dissociation التي في الفنون والأدب، منذ سيزان cezanne sensibility Baudelaire، وقد أصبحت من أهم العوامل في كل برنامج إصلاحي من أجل ترقية الذوق والمعرفة[51]".

وهكذا يرى أن ذلك التحرر والانفصال قد ساعدا على تتمية القدرة على

التجزئة الذاتية والإبداع في الفن والأدب، وأصبح إنسان الطباعة متسلحًا بروح المغامرة الثخصية (private enterprise) التي شجعت المؤلفين والفنانين على تتمية التعبير الذاتي، وهي نفس الروح التي قادت الآخرين لكي يخلقوا المؤسسات العملاقة سواء في التجارة أو غيرها.

ومن الطريف هنا أن نلاحظ الربط بين ظهور المشروع الفني والأدبي المنطلق من روح الإبداع والمغامرة الشخصية، وبين المشروع أو المؤسسة العملاقة في مجال التجارة أو الصناعة، المتأثرة بنف الروح المتسمة بانطلاق الدوافع الذاتية، وهي روح المشروع الرأسمالي في أوروبا عصر النهضة التي خلعت أثواب الإقطاع وأشكال التبعية سواء للإقطاعي أو للكنيسة.

\section{ثانيًا: التأثثرات الثقافية والاحتماعية للمطبوع:}

\section{7. تغيير طبيعة التأليف:}

وكان لهذا التأثير الفضل في في تأكيد الوحدة الموضوعية للعمل الأدبي، وأصبح الأديب والجمهوري قادرين على ذلك. "فقلد أثرت خاصية الاتساق 
Uniformity واتجاهًا مميزين، وأصبح هناك موضوع يتخلل كل تكوين العمل الدكتوب"[53.

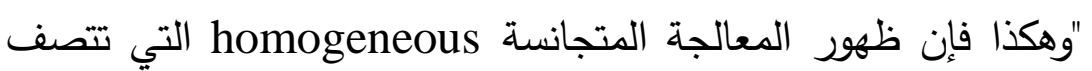
بكل من التميز والعقق، قد مكنت الكاتب من الوصول إلى الجمهوري العريض Mass piblic

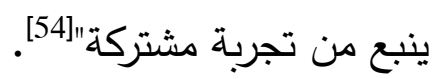
ونلاحظ أن جون ديوي قد توصل إلى هذه الملاحظة قبل ماكلوهان؛ حيث

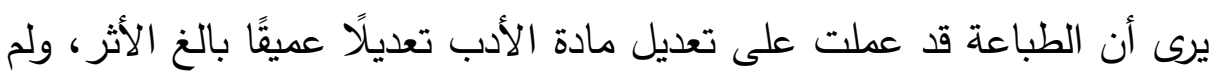

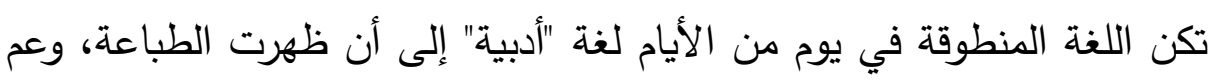

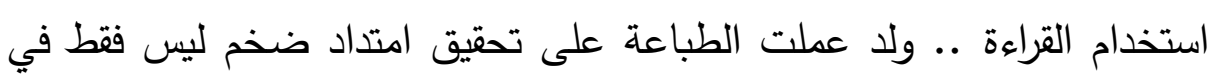

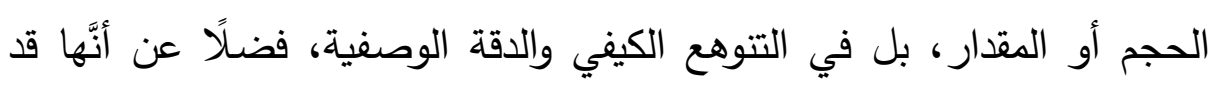
أوجدت منظمة لم يكن لها وجود من قبل [55]. وثمة ملاحظة أخرى شديدة الأهمية، يذكرها ديورانت في قصة الحضارة، وهي أن الطباعة قد أثرت في نوع الأدب وقوامه بإخضاع المؤلفين لجيوب الطبقات

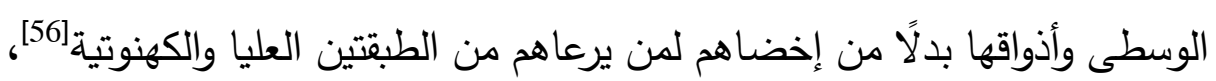

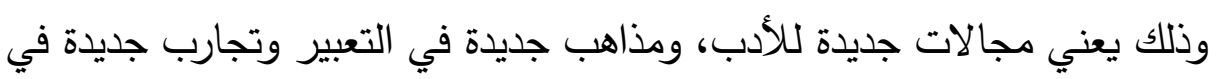

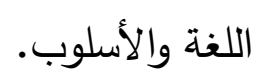
8. ظهور الجمهور:

"وقد خلقت الطباعة بواسطة الحروف المتحركة، بيئة جديدة وغير متوقعة تماءًا، خلت الجمهور Puplic. ذلك أن تكنولوجيا المخطوط لم تكن لها قوة

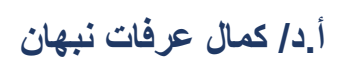
(حضارة الكتاب... نظريَّة في الثََّثيرات الحضاريَّة... ) 
الامتداد الضرورية لخلق جمهور على مدى قومي[57]. ولكن تكنولوجيا المطبوع، بإمكانياتها الجديدة، أتاحت "التكرار الآلي لنفس النص، الذي خلق جمهورًا قارئًا"[58]. وخرجت صفحة الكتاب، في شكل صورة متكلمة للحياة العادية، فحدث shift from As the crucial" [59] التحول الحاسم من الزبون إلى الجمهور patron to piblic يستطيع الحصول على المخطوط باهظ التكاليف، "ووصل الكاتب إلى الجمهور العريض المتجانس بطريقة دائمة وكافية في مجتمع السوق Market society الذي أوجده المطبوع، وتحولت صورة انتقال الفكرة من إطارها الضيق قبل ظهور الطباعة إلى جمهور القراءة الواسع، الذي يعتمد على النظرة ذات الثبات الآلي في حالة الاعتماد على الرؤية، بدلًا من جماعة المستمعين auditoy [61]" وقد أتاح ذلك الروح الاستقلالية لدى الجمهور في موازاة التعبير الذاتي لدى الأديب. 9. ظهور الأديب:

وبهذا التطور الذي خلق التحرر والانفصال والقدرة على التجربة الذاتية والإبداع في الفن والأدب، والذي خلق الجمهور العام بعد الامتداد الطباعي الجديد، والتطور الجديد في شكل التأليف والكتابة وظهور الوحدة الموضوعية في عملية التأليف، والعلاقة الجديدة بين الكاتب وجمهور أو جماهير واسعة ليست بينها معرفة بالتحديد. بهذا التطور "وُلا الأديب أو رجل الأدب Man of letters"][2]، (الذي يتفرغ للتأليف في موضوعات أدبية)، والذي أصبح يكتب للجمهور بدلًا من مخاطبة الزبون (ملكًا أو غنيَّا أو صاحب جاه) في عصر المخطوط المتصف بالندرة والخصوصية وارتفاع التكلفة، وحسب تعبير ماكلوهان، فقد شهد عصر 
المخطوط وجود المؤلف (auther) أما الأديب (Man of letters) فهو نتاج عصر المطبوع؛ حيث استطاع أن يصل إلى جمهور عريض متجانس مع الإنتاج الواسع للمطبوع[63]

\section{0. ظهور أثكال جيدة من الأبب:}

ولقد تراكمت كل هذه التطورات في طبيعة التأليف، والكتابة، وفي العلاقة

الجديدة بين الكاتب "وجمهوره" وفي نمو روح التعبير الذاتي، والمهارات والخصائص

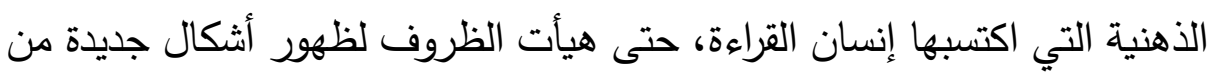
الأدب والفن. ويذكر ماكلوهان أنه "توجد إثارات غير مباشرة، عن التأثيدات الثيرات التي

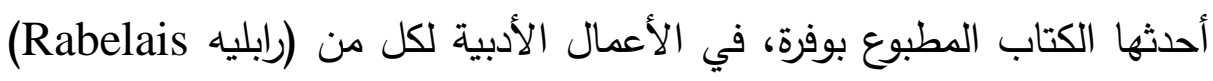
(1495 - 1553)، وسرفانتس Cervantes (1547 - 1616م) ومونتيني 1592 1533) Montaigne (1592)، وسويفت Swift (1667 - 1745) وبوب Pope

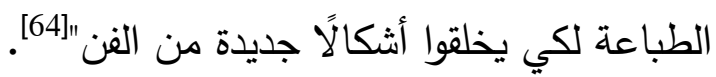

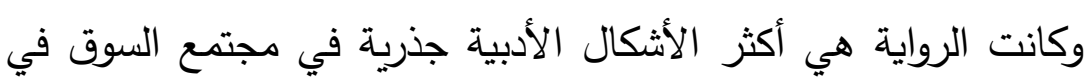
القرن 18، وكان قد سبقها النثر الموزون "Equiton prose" ... وهذا التقدم

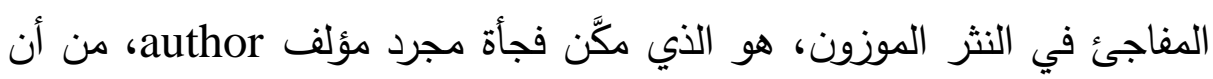

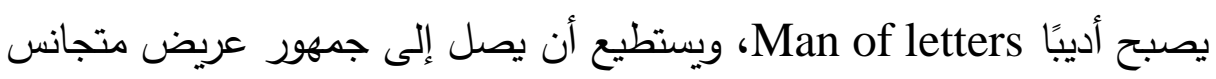
في مجتمع السوق[65].

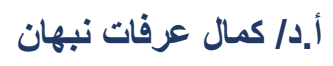
(حضارة الكتاب... نظريَّة في الثَأثيرات الحضاريَّة... ) 


\section{1. تطوير فروع جيدة في العلم:}

"ولقد كان التعليم كله تقريبًا قبل جوتتبرج في يد الكنيسة في أوروبا، وكانت

الكتب المخطوطة باهظة الثن، وكان النسخ مجهًِا وغير معتتى به أحيانًا، واستطاع عدد قليل من الكتاب الوصول إلى جمهور كبير ولكن بعد زمن من وفاتهم [68]. كما غيَّرت الطباعة من نظام الدراسة والتعليم، فكان الكتاب أول آلة تعليمية بعد أن أصبح أول سلعة تنتج بالجملة]69] في تاريخ الإنسان. وقد أشرنا إلى أن عصر المخطوط كان هو عصر الزبون؛ حيث كان يتم تقصيل الطلب وهو (المخطوط) حسب إمكانيات الزبون ورغباته، أما عصر المطبوع فهو عصر الجمهور لأن المطبوع ينتج بالجملة وبشكل متماثل في الطبعة الواحدة. وهكذا فقبل الطباعة كما يلاحظ ماكلوهان، كانت ثقافة المخطوط تساند عملية شفهية في التعليم، سُميت بالمدرسية أو الإسكولائية (Scholastisim) (التي امتدت بمعناها الواسع من القرن 9 الميلادي إلى نهاية القرن 14 أو بداية القرن 15 الميلادي)، ولكن بعد أن وفر المطبوع نفس النص أمام أي عدد من الطلاب أو القراء، سرعان ما انتهى النظامم الإسكولائي (المدرسي) للمناظرة الشفهية، وقد وفر المطبوع ذاكرة جديدة واسعة (أي ذاكرة ورقية)، تحفظ كتابات الماضي، مما جعل الذاكرة الشخصية غير كافية أو لا يعول عليهات[70]. "وقد هيأت الطباعة لدعوة لوثر بالتحول من الاحتكام إلى البابوات إلى الاحتكام إلى الإنجيل، وسمحت بعد ذلك بدعوة العقليين إلى الاحتكام إلى العقل، وقضت على الاحتكار الكهنوتي للتعليم، ويسرت الاتصال والتعاون بين العلماء على مستوى دولي [71]. 


\section{2. ظهور وتحيد الوظائف والتخصص الدقيق:}

وكان للامتداد الطباعي الإنساني نتائج اجتماعية أخرى متعددة، تولدت

عنها ظواهر جديدة، من أهمها التصنيع والأسواق العامة، فقد وفرت الطباعة أو لسلعة Commodity قابلة للإنتاج المتكرر المتماثل

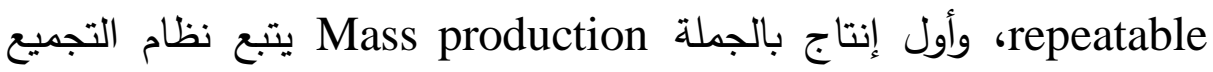
line Assembly ولك يكن ذلك موجودًا في إنتاج أية سلعة سابقة على المطبوع، وقد تحقق ذلك نتيجة لما وفرته الطباعة من الاستمرارية Continuity والتماثل Uniformity والتكرارية، وهي من أسس الإنتاج الصناعي والتسويق[71]. كما أن الطباعة غيرت من عمليات التسويق[777؛ حيث كان الكتاب أيضًا أول سلعة يمكن أن تحمل سعرًا محددا، وهكذا وجد شكل محدد لنظام السعر، ولم يكن غرببًا أيضًا أن يظهر في هذه البيئة الجديدة مفهوم العجلة والآلة وخط الإنتاج المتتابع، وكلها أفكار ميكانيكية تتمشى تمامًا مع وسيلة الطباعة بحروفها المرصوصة جنبًا إلى جنب في شكل أسطر محتوية على كلمات متتالية[78].

\section{5. ظهور القومية:}

تحتل مسألة ظهور القومية Nationality لدى أمم العالم احتمام كثير من المؤرخين وعلماء السياسة والاجتماع، ومن بين التفسيرات الهامة للعومل التي أدت إلى ظهور القومية، تفسير ماكلوهان الذي نعرضه هنا، فبعد أن اتضح كيف أتاح الامتداد الطباعي للإنسان فرصة وجود جمهور قارئ، وظهرت صورة الجمهور 
التي بدأت تتسع بمرور الزمن، أصبح من الممكن "ظهور جماهير على مدى قومي، بعد أن كانت تكنولوجيا المخطوط عاجزة عن ذلك"[79]. "ولقد مكنت الحروف الهجائية (وامتدادها عن طريق الطباعة) من

امتداد قوة المعرفة، وحطمت روابط الإنسان القبلي، وبذلك جزأته داخل تكتل يتكون من الأفراد"[80. "وأصبح الإنسان الذي خلقت لديه القدرة على التفكير المنفصل عن الانفعال أو الشعور ، يمتلك القدرة على الفعل المستقل، وانفصل عن العالم القبلي ذي الروابط الأسرية القومية التي تتحكم في الحياة الثخصية والاجتماعية"[81]. وهكذا فإن تحطم العلاقات والروابط التقليدية الثَبَلية، وظهور استقلال الفرد وعدم انضوائه في هذه الإطارات القديمة الضيقة، نتيجة للقوة الانفصالية التي تتمي ذاتية الفرد؛ حيث أوضحنا ما تقوم به القراءة من انفصال ثم اتصال، أس انفصال عن العلاقات الضيقة في الجماعة التقليدية، واتصال بآفاق أوسع وأفكاره واردة من الآخرين على اتساع رقعتهم وانتماءاتهم، في إطار ذلك ظهرت نتائج اجتماعية وسياسية خطيرة؛ حيث يلاحظ ماكلوهان "أن ما أطلقنا عليه اسم أمم Nations في القرون المعاصرة، لم يسبق ولم يكن الممكن أن يسبق مجيء تكنولوجيا جوتنبرج"[82]، فقد أوجد المطبوع أشكالًا جديدة تمامًا لتوسيع وامتداد الطاقات الاجتماعية، وبعث طاقات نفسية واجتماعية هائلة في عصر التهضة، كما هو الآن في اليابان أو روسيا، وذلك بإخراج الفرد من جماعته التقليدية، وظهور شكل جديد من العلاقات ينضم فيه فرد إلى فرد، في تكتل جماهيري عظيم من القوة

أ.د/ كمال عرفات نبهان (حضارة الكتاب.. نظريَّة في الثتَّثيرات الحضاريَّة... ) 
ويستند ما يرصده ماكلوهان من نتائج اجتماعية أدت إلى ظهور القومية، إلى أساسين:

1. تأكيد استقلال الفرد ونظرته الموضوعية المتجردة، التي تمكنه من فهم

$$
\text { الآخرين والاقتراب منهم نفسيًا وفكريًّا. }
$$

2. إمكانية ظهور جماعة أكبر يرتبط بها الفرد، وهي الأمة، مما يعني

$$
\text { ظهور القومية. }
$$

وفي دراسة عن المجتمعات النامية، أشار ليرنر Lerner إلى صفة التفتح السمح، والاستشعار بالغير Empathy، هي الصفة الأساسية الهامة في تطور المجتمع النامي ... والاستثعار بالغير بكل بساطة هو القدرة على أن يرى الإنسان نفسه في موضع الشخص الآخر ، وهذه مهارة لا غنى عنها لمن خرجوا من حجرة المجتمع التقليدي .. والاستشعار بالغير هو الأسلوب الثخصي الغالي في المتمع المصري وحده، فهذا المجتمع يتيمز بكونه صناعيًّا، حضريًّا، متعلمًا، ومشاركًا، والمجتمع التقليدي لا مشاركة فيخ، فهو يوسع نطاق الناس عن طريق القرابة، ويجعل منهم مجتمعات معزولة بعضها عن بعض، ومعزولة عن مركز ما"[84]. ولعل ذلك يلقي الضوه على كثير من المشاكل التي تعترض تطور المجتمعات التي مازالت في طريق النمو وتعطي تفسيرًا لأوضاعها الاجتماعية، يعالج جذور المشكلة من الناحية النفسية والاجتماعية، فمعظم النتائج الاجتماعية التي ينسبها ماكلوهان إلى حضارة الطباعة والقراءة، تفتقدها المجتمعات التي لم تعش هذه المراحل الحضارية. ورغم مرور خمسة قرون على ظهور الطباعة، فإن "التعليم لا يزال هو الظرف العام المحيط، في جزء صغير من العالم، ومازالت

أ.د/ كمال عرفات نبهان (حضارة الكتاب.. نظريَّة في التَّثيرات الحضاريَّة... ) 
أمريكا اللاتينية وآسيا وإفريقيا وأجزاء من أوروبا في مرحلة ما قبل التعلم، ولذلك فإن تكوينات الظروف المحيطة بهذه المناطق مازالت تعتمد على السماع"[85]. ومازالت علاقات الأفراد فيها تقوم على أسس وارتباطات قَبَليَّة أو ضيقة، ومازالت تفتقد هذه المراحل التحليلية التركيبية، التي فككت علاقات الإنسان القبلي وأدمجته في جامعة أكبر، ومهدت لظهور القومية كثمرة من ثمار حضارة القراءة، ولعل ذلك يعطي مزيدًا من الفهم لما يحدث لفكرة القومية في العالم العربي من امتداد وانتكاس، نتيجة لتعدد المراحل الحضارية والقرائية التي يمر بها كل مجتمع محلي من المجتمعات العربية. وينبغي ألا نفهم نظرية ماكلوهان بخصوص تأثيرات المطبوع بطريقة سطحية أحادية البعد، بل يجب أن نتسلح بالنظرة الجدلية التي ترى الثيء ونقيضه مُجتمعين معًا، وبعمق فكرتنا عن تأثير القراءة ملاحظة ثاقبة ذكرها ويليام جراي ف.Gray قبل ظهور الطباعة بعشرات القرون - قد خدمت غايتين على طرفي نقيض: (أ) فهي من جهة كانت قوة موحدة عظيمة، تميل إلى توحيد الفرق الاجتماعية (Socisl groups) عن طريق الإمداد بخبرات مشتركة وبديلة Common and vicarious، وتربية اتجاهات ومُنُل

$$
\text { وتطلعات مشترَكة. }
$$

(ب) ومن جهة أخرى قامت بدور القوة المحطَّمة التي تجنح إلى تعظبم الفروق بين الفرق الاجتماعية، وذلك بتدعيم الآراء المتباعدة، وهكذا خدمت القراءة كلًّ من غايتي البناء والهدم [86]. 
ومن الواضح أن ماكلوهان يضع في اعتباره مجتمع الطباعة الذي خلق الجمهور القارئ والإنتاج الواسع للمطبوع، ولم يضع في اعتباره قضية معرفة مجتمع ما للكتابة، وإلا كان مسئولًا عن التفسير الحضاري لأبعاد أخرى كثيرة ترتبط باختراع الكتابة والحضارات القديمة التي أبدعتها، وذلك موضوع لم يتدخل فيه ماكلوهان، بل اعتبر كل مجتمع لم يتعلم القراءة بشكل جماهيري مجتمعًا شفهيَّا، حتى ولو كان من أقدم المجتمعات رسوخًا في الحضارة؛ لأن القراءة في هذه المجتمعات ليست جماهيرية حتى الآن. ومن الواضح أيضًا أن دراسة الحضارة الإسلامية مازالت تحتاج إلى دراسة أكثر تعمقًا سواء على ضوء نظرية ماكلوهان أو ضوء مناهج ونظريات أخرى؛ لأن الحضارة الإسلامية هي حضارة "الكتاب" أو النص وهو القرآن الكريم الذي تبلورت وازدهرت حوله حضارة هائلة، ولم تتأثر أمة أو حضارة مثلما تأثرت الحضارة الإسلامية بنص القرآن الكريم، فقد نشأت حوله علوم كثيرة لخدمته وتفسيره، ونشأت كيانات معرفية مستقلة وشامخة بنيت على هذه العلوم المساعدة، حتى كونت ثقافة متكاملة في تاريخ الحضارة الإسلامية. ولكن تفسيرات ماكلوهان للحضارة على ضوء حضارة جوتنبرج، تعطينا فرصة هائلة لتأمل الماضي والحاضر والمراحل الاجتماعية والفكرية والنسب الانفعالية والإدراكية التي يعيشها كل من المجتمعات العربية، سواء في ظل بقايا ثقافته الثفهية أو تقدماته القرائية الطباعية، وخصوًا وأن حضارة الكتاب مهددة بوسائل الاتصال الثفهية الإكترونية الحديثة، التي تكاد في بعض البلدان النامية ترث مباشرة المراحل الثفهية القديمة، مع اختزال المراحل القرائية التي بنيت عليها 
مقومات الحضارة الغربية في صورها الصحية الثامخة، وليس في صورها المتهالكة التي ننشغل بها في رؤية أُحادية مجزوءة. كما أن من المهح أن نوضح أن أفكار ماكلوهان وتفسيراته رغم براعتها وإبداعها وقيمتها العلمية، لا يمكن أن تتسب كل الفضائل للثقافة الكتابية الطباعية فحسب، بحيث ننكر كل فضائل ما قبل هذه الثقافة، أي الثفاهية القديمة والحالية، والمستقبلية.

وإذا كانت هذه الدراسة قد نجحت ولو بدرجة متواضعة في عرض أفكار

ماكلوهان ومنهجه، بحيث تثير لاى القارئ ردود أفعال متعددة تتراوح ما بين التأييد لبعض أفكاره والاعتراض أو التحفظ على البعض الآخر، فإن ذلك هو أعز ما يطمح إليه الباحث؛ لأن الأفكار المبدعة هي التي تثير القلق والتساؤل، وتحفز العقل لدراستها وبحثها؛ لتستمر جدلية الإبداع والابتكار، وليس من الممكن أن تظهر نظرية صحيحة بصورة مطلقة، ويكفي أن تطرح النظرية مزيدًا من الفهر للظواهر والعلاقات الخفية والكامنة. وثمة جوانب هامة في نظرية ماكلوهان، تتعلث بما يطرحه بالنسبة لتأثيرات وسائل الاتصال الإلكترونية الحديثة كالراديو والتليفزيون، وهي مجال خصب لمزيد من الدراسات في المستقبل بمشيئة الله. 


\section{الهوامش}

1. انظر في هذا الموضوع الكتاب التالي: حسني الثيمي: الورقية واللاورقية؛ أو

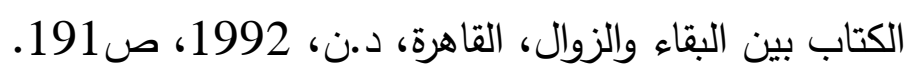

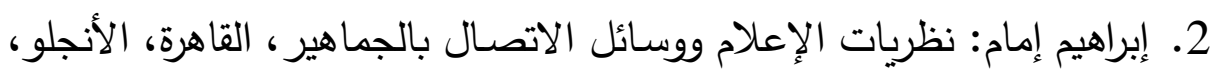

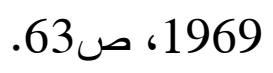

3. أونج، والتر : الثـــفاهية والكتابية، ترجمة حســـن البنا عز الدين، الكويت،

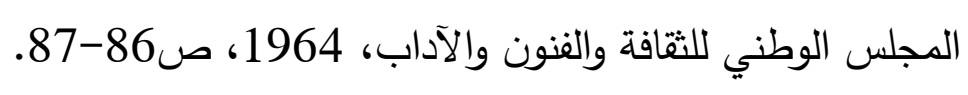

4. ديورانت، ول: قصـة الحضــارة، مج6 ج1 (22)، ترجمة عبدالحميد يونس،

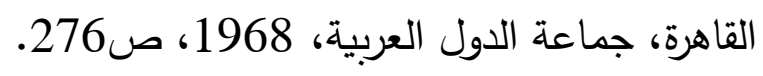

5. Spengler, Oswald (1880-1936): The decline of the West, N.Y, A. A. Knopf, 1932 Vol 2, P. 461-63.

$$
\text { 6. أونج، والتر ج: الثفاهية والكتابية.. ص73-74. }
$$

8. Waples, D., B. Berelson \& F. R .Bradshaw: What reading does to people: a summary of evidence on social effects of reading, Chiago, Chicago ,Univ.Pr., 1940.

9. Winger, Howard W. "Historical perspectives on the role of the book in society", L.Q.Vol.25 (1955), P. 295-305.

$$
\text { 10. أونج، والتر ج: الثفاهية والكتابية ... ص87. . }
$$

11.McLujan, M. Understading media: the extensions of man . N,Y., The New Am. Lib., 1966, P. 156.

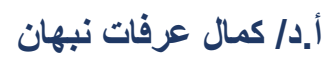
(حضارة الكتاب... نظريَّة في الثََّثْرات الحضاريَّة... ) 
12. ظهرت ترجمة عربية لهذا الكتاب بياناتها: (ماك لوهان، مارشــال: كيف

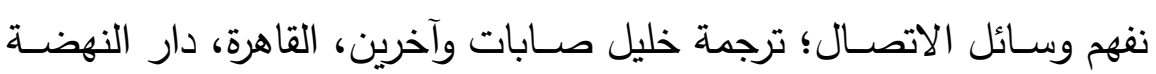

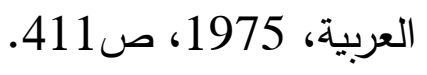

13.McLuhan, M.The Gutenberg galaxy: The making of typographic man. Toronto, Univ.of Toronto Pr., 1962, P.265.

14.McLuhan, M.The medium is the message, London, Routledge \& Kegan Paul, 1973, P. 26.

15.McLuhan, M. Understading media: the extensions of man . P 156.

16.McLuhan, M.The medium is the message, P.31-32.

17.McLuhan, M.The Gutenberg galaxy, P.4.

18.McLuhan, M.The medium is the message, P.38-39.

19.McLuhan, M.The Gutenberg galaxy, P.4.

20.McLuhan, M.The Gutenberg galaxy, P.40.

21.Ibid, P.34-37.

22. إبراهيم إمام: نظريات الإعلام ووسائل الاتصال بالجماهير ... ص64.

23. جيهان رشتي: الإعلام ونظرياته في العصر الحديث، القاهرة، دار الفكر

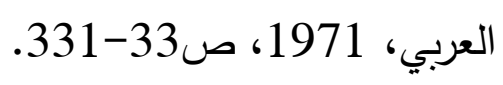

24.McLuhan, M.The medium is the message, P.22

25.Ibid, P.41.

26.Ibid, P.154.

$$
\begin{aligned}
& \text { 27. جيهان رشتي: المرجع السابق، ص346. } \\
& \text { 28. المرجع السابق: 342-343. } \\
& \text { 29. المرجع السابق: 331. }
\end{aligned}
$$

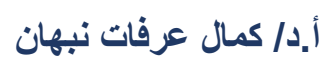

(حضارة الكتاب... نظريَّة في الثََّّيرات الحضاريَّة... ) 
30.McLuhan, M.The medium is the message, P.5

31.McLujan, M. Understading media, P. 157.

32.Ibid

33.McLuhan, M. "The cool Medium", Cantor, Norman F. and

Micheal S. Werthman (eds.): The history of popular

culture. N.Y, Macmillan ,1968 ,P. 723.

34.McLujan, M. Understading media, P. 158.

35.Ibid, P.157.

36.McLuhan, M.The medium is the message, P.50.

$$
\begin{aligned}
& \text { 37. أونج، والتر : المرجع السابق، ص110. } \\
& \text { 38. المرجع السابق، ص86. }
\end{aligned}
$$

39.McLujan, M. Understading media, P. 157.

40.Ibid, P.162.

41.McLuhan, M.The medium is the message, P.156.

42.McLuhan, M. "The cool Medium”, P.723.

$$
\text { 43. جيهان رشتي، المرجع السابق، ص.340-341. }
$$

44.McLuhan, M.The medium is the message, P.157.

$$
\text { 45. جيهان رشتي، المرجع السابق، ص340. }
$$

46.McLuhan, M. “The cool Medium”, P.723.

47.McLuhan, M.The medium is the message, P.50.

48.McLujan, M. Understading media, P. 157.

49.Okasha, Sarwat: An encyclopaedic dictionary of cultural terms, Cairo, Egypt, Intern, Publishing Co. Longman, 1990, P. 101.

50.McLujan, M. Understading media, P. 157-158.

51.Ibid, P.157.

52.Ibid.

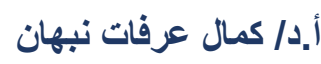

(حضارة الكتاب.. نظريَّة في التَّتثيرات الحضاريَّة... ) 
53.Ibid, P.162.

54.McLuhan, M.The Gutenberg galaxy, P.273.

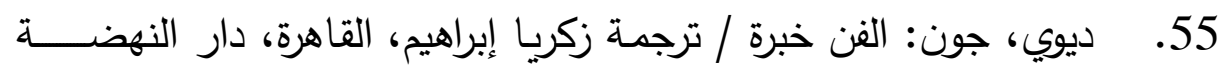

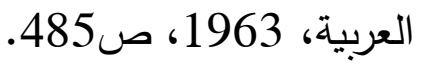

$$
\begin{aligned}
& \text { 56. ديورانت، ول: المرجع السابق، ص281-282. }
\end{aligned}
$$

57.McLuhan, M.The Gutenberg galaxy, P. (A).

58.McLuhan, M.The medium is the message, P.122.

59.McLuhan, M.The Gutenberg galaxy, P. 274.

60.Ibid, P.273.

61.Ibid.

62.McLujan, M. Understading media, P. 162.

63.McLuhan, M.The Gutenberg galaxy, P. 273.

64.McLujan, M. Understading media, P. 157.

65.McLuhan, M.The Gutenberg galaxy, P. 273.

66.McLujan, M. Understading media, P. 161.

$$
\text { 67. ديورانت، ول، المرجع السابق، ص276. }
$$

68.Ibid, P.157.

69.Ibid, P.158.

70.Ibid.

$$
\text { 71. ديورانت، ول، المرجع السابق، ص281-282. }
$$

72.McLujan, M. Understading media, P. 159-160.

$$
\text { 73. جيهان رشتي، المرجع السابق، ص336-338. }
$$

74.MC Luhan, M: Op. Cit, P.159-160.

75.McLuhan, M.The medium is the message, P.50.

76.McLujan, M. Understading media, P. 161.

77.Ibid, P.158.

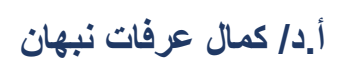

(حضارة الكتاب.. نظريَّة في التَّثيرات الحضاريَّة... ) 
78. إبراهيم إمام، المرجع السابق، ص64.

79.McLuhan, M.The Gutenberg galaxy, P(A).

80.McLujan, M. Understading media, P. 156.

81.Ibid, P.158.

82.McLuhan, M.The Gutenberg galaxy, $\mathrm{P}(\mathrm{A})$.

83.McLujan, M. Understading media, P. 157.

84. شـــرام، ولبور : أجهزة الإعلام والتتمية الوطنية: دور الإعلام في البلدان

النامية، القاهرة، الهيئة المصرية العامة للتأليف، 1970، ص171-172.

85. جيهان رشتي: المرجع السابق، ص340.

86.Gray, W.S "Reading". (Encyclopaedia of Education Research.. P.967-968. 


\section{قائمة بيليوجرافية}

1. إبراهيم إمام: نظريات الإعلام ووســائل الاتصـــال بالجماهير، القاهرة، مكتبة الأنجلو، 1969.

2. أونج، والتزر ج: الثـــفاهية والكتابية، ترجمة حســن البنا عز الدين، الكويت، المجلس الوطني للثقافة والفنون والآداب، 1994.

3. جيهان رشتي: الإعلام ونظرياته في العصر الحديث، القاهرة، دار الفكر

$$
\text { العربي، } 1971 .
$$

4. ديورانت، ول: قصــة الحضــارة، مجلد 6، ج1 [22]، ترجمة عبدالحميد

$$
\text { يونس، القاهرة، جامعة الدول العربية، } 1968 .
$$

5. ديوي، جون: الفن خبرة، ترجمـة زكريـا إبراهيم، القـاهرة، دار النهضـــــة

$$
\text { العربية، } 1963 .
$$

6. شــرام، ولبور : أجهزة الإعلام والتتمية الوطنية.. دور الإعلام في البلدان

النامية، القاهرة، الهيئة المصرية العامة للتأليف والنشر ، 1970.

7. Gray, W. S: "Reading: Sociology of reading". (Encyclopaedia of Educational Research, ed.by W.S. Monroe. N.Y ,Macmillan, 1950, PP.967-971.

8. Mc Luhan, Marshall: "The cool medium: in) Cantor, Norman F \& .Michael S. Werthman (eds): The history of popular culture. N.Y, Macmillan, 1968, PP718-726.

9. Mc Luhan, M: The medium is the message ..London, Routledge \& Kegan Paul, 1973. 
10.Mc Lihan, Marshall: Understanding media: the extensions of man, N. Y. The New American Library, 1966.

11.Okasha, Sarwat: An encyclopaedic dictionary of cultural terms. Cairo, Egyotion International Publishing Co, Longman, 1990.

12.Spengler, Oswald (1880-1936): The decline of the West ,N. Y, A.A. Knopf, 1932.

13.Waples, Douglas, B. Berelson, F.R. Bradshaw: What reading does to people? A summary of evidence on the social effects of reading,Chicago, Chicago Univ. Pr., 1940.

14.Winger ,Howard W. "Historical perspectivrs on the role of the book in society), "Library Quarterly, Vol 25, 1955, PP.295-305. 